\title{
SPIROMETRIC ASSESSMENT OF LUNG TRANSPLANTED PATIENTS: ONE YEAR FOLLOW-UP
}

\author{
Avaliação espirométrica de pacientes submetidos a transplante pulmonar: um ano de seguimento
}

\author{
Paulo Pêgo-Fernandes, Fernando Conrado Abrão, Frederico Leon Arrabal Fernandes, Marlova Caramori, \\ Marcos Naoyuki Samano, Fabio Jatene
}

\begin{abstract}
Purpose: The purpose of this study was to compare spirometric data between patients submitted to single-lung and double-lung transplantation along the first year after the transplant procedure. Introduction: Lung transplant was first described as an experimental method in 1963; it became a therapeutic option for patients with advanced pulmonary diseases due to improvements in the organ conservation, surgical techniques, immunosuppressive therapy, and treatment of post-operative infections. Methods: We retrospectively reviewed records of 39 patients, who received lung transplantation in our institution between August, 2003 and August, 2006. The Post-transplant survival after 1 year occurred in 29 patients, and all of them were followed-up. Results: Increase of the lung function in double-lung transplant group occurred earlier, presenting statistical difference after the 1st month both in the FEV1 and FVC compared to pre-transplant values (p $<0.05$ ). As to the group of patients with emphysema, comparison between two groups showed from the 3rd month a difference of the lung function. Discussion: Both analysis of the whole group added to the subgroup of emphysema patients supplied relevant data that points out the advantage of the bilateral over the unilateral transplantation. Although values of pre-transplant lung function were worse in the double-lung group, such difference did not occur again in the subsequent months to the surgery. Conclusion: There was a clear tendency to higher and earlier improvement in FVC and FEV1 in the bilateral transplant group.
\end{abstract}

Keywords: Lung Transplantation; Spirometry, Respiratory Function Tests, Emphysema

Instituição:

Disciplina de Cirurgia Torácica do Instituto do Coração, São Paulo/SP

\section{Correspondência:}

Paulo M. Pêgo-Fernandes

Av. Dr. Enéas de Carvalho Aguiar, 44 - $2^{0}$ andar - sala 9 - São Paulo / SP - CEP: 05403-000 Brasil

Tel.: (11) 30695922

E-mail: paulopego@incor.usp.br

Recebido em: 15.12 .2008

\section{INTRODUCTION}

In agreement with the International Society for Heart and Lung Transplantation, the transplant is indicated for patients with advanced uncontrolled chronic pulmonary disease or those who had no efficiency from the medical treatment, despite the maximal medical therapy. ${ }^{1}$

Initially, only pulmonary fibrosis was indicated to receive lung transplantation. ${ }^{2}$ However, indications have been expanded: Cystic fibrosis, primary and secondary forms of pulmonary hypertension $(\mathrm{PH})$, bronchiectasis, and chronic obstructive pulmonary disease (COPD) primarily the emphysema phenotype. ${ }^{3}$

Chronic Obstructive Pulmonary Disease (COPD) is considered to be the fifth leading cause of death around the world by $2020 .{ }^{4}$ For many years, the only treatment improving the survival in patients with advanced COPD was chronic home oxygen therapy. ${ }^{5,6}$ Since the 1990s, however, orthotopic lung transplantation has proved to be an effective therapeutic alternative, although indication for such procedure is restricted when using the criteria of age, co-morbidity, and surgery feasibility.

It has been proved the post-transplant survival benefits in patients with advanced pulmonary fibrosis and PH. For patients with cystic fibrosis and COPD, such benefit is still being questioned; the gain in quality of life and physical activity tolerance appears to be more important. ${ }^{8-12}$ 
Double-lung transplant is necessary in suppurative diseases that attack both native lungs. In these cases, the persistence of an infected lung in transplanted individuals in need of immunosuppressive therapy can lead to infectious exacerbations and risk of respiratory complications, such as chronic sputum production and progressive post-operative physical limitation.

Since the technique of unilateral transplant is simple and demands less surgical time, initially patients with non-suppurative diseases such as emphysema and pulmonary fibrosis are often transplanted using this modality. ${ }^{13}$

However, even in non-suppurative diseases there seems to be major improvements when bilateral transplant is carried out. As an example, COPD bearers subjected to bilateral transplant present better lung function and trend to improve their long-term survival in spite of an apparent equity between both methods when considering tolerance to exercises and quality of life. . $^{3,14}$

Since its initial description, the survival of transplanted patients is increasing. At this time, some centers present a higher than $80 \%$ one year survival, with mean $60 \% 3$ years survival. With the increased life expectation, it is important to study the follow-up methodology and long term controlling, in order to make rapid and accurate diagnosis of infectious complications and rejection. ${ }^{15}$

Spirometry is used in the transplanted patients' follow-up. Assessment of forced expiratory volume in the first second (FEV1) and in forced vital capacity (FVC) is a reproducible method to screening complications, like rejection, bronchiolitis obliterans and infections. Nevertheless, such method has low diagnosis specificity as to the type of complication.

In the case of unilateral transplants, there is still one more trap when interpreting spirometric data. The fall in the FEV1 can be a consequence of the mentioned complications, as well as the progression of the disease or hyperinsufflation in the native lung.

Higher than $11 \%$ and $12 \%$ decreases in FVC and FEV1, respectively are considered significant in the bilateral transplantation. Likewise, higher than $12 \%$ and $13 \%$ decreases in FVC and FEV1, respectively are significant in unilateral transplant. These results demand the need to further investigate organ rejection or infection. ${ }^{16}$

As previously noted, the surgical technique for bilateral transplant demands more hard work than unilateral transplant. Nevertheless, if that kind of surgery presents long term advantages for the transplanted patient, it must be carried out. Still, there is not a final answer as to the advantages of the bilateral transplant in non-suppurative pulmonary diseases. Recent data shows that spirometry in double-lung transplant is marginally advantageous to single-lung in emphysema. ${ }^{17}$

The purpose of this study was to compare spirometry data between patients submitted to single-lung and double-lung transplantation along the first year after the transplant procedure.

Our goal was to demonstrate if there is better gain in pulmonary function and persistence of such increment in the one year followup of bilateral lung transplant, adding one more landmark that this kind of transplant is better than the unilateral modality.

\section{METHODS}

We retrospectively reviewed records of 39 patients who received lung transplantation in our institution between August 2003 and August 2006. The Post-transplant survival after 1 year occurred in 29 patients, and all of them were followed-up. Another 10 patients (09 single-lung transplantation and 01 double-lung transplantation) died in the first post-operative year. These patients were excluded from the study.

The follow-up after the hospital discharge was performed weekly up to the end of the third month, becoming monthly or bimonthly from that period on. In all visits, the patient's pulmonary function was assessed through radiological examination and blood tests.

Spirometric values of the 29 patients who undergone by lung transplant with more than 1 year survival were analyzed. The FVC and FEV1 values were analyzed as a percentage of the forecast from the patient's last test before the transplant, and 1, 3, 6, and 9 months and one year post-operative.

All spirometric measurements were carried out in accordance to the international proceedings using a portable spirometer (Koko Spirometry; Pulmonary Data Services Instrumentation, Inc, Louisville, Lap) or pletsmograph (MedGraphics Elite Dx System, St Paul, MN). Results were expressed in absolute values and the percentage of the forecast was calculated using Knudson et al equations. ${ }^{18}$ Tests were always carried out in the morning (Mondays from 8:30 to $11: 30 \mathrm{am}){ }^{19}$

Patients were divided in two groups, according to their type of lung transplant: 11 single-lung patients, and 18 double-lung patients. Each group had pre- and post-transplant measurements (1, 3, 6, 9, and 12 months) performed.

Each measurement passed by a normality test (KolmogorovSmirnov). The spirometric evolution of each group in the pretransplant up to one year post-operative was compared using the analysis of variance (ANOVA). Comparative analysis between unilateral and bilateral transplants was performed using the $\mathrm{t}$-Student test for the average comparison. The value of significance attributed was alpha $=0.05$.

The sub-group of patients with pulmonary emphysema (5 unilateral and 4 bilateral transplants) was analyzed separately using the same statistical methodology. Statistical calculations were carried out using the Sigma Plot V10.0 (SPSS, Chicago, IL).

\section{RESULTS:}

\section{Demographic features and lung function in pre-transplants:}

The lung function of eighteen patients who undergone by bilateral lung transplant and eleven patients subjected to unilateral transplant were analyzed. Chart 1 shows baseline data of each group of patients. There was difference in the FVC and FEV1 on pre-transplant spirometry between unilateral and bilateral transplant $(p=0.002$ and $p<0.001)$. Patients who undergone by double-lung transplant presented worst lung pre-transplant function. CVF of transplanted double-lung recipients presented an average 14\% lower than the unilateral transplant group. The difference of preoperative VEF1 was $11 \%$. The mean age in both groups also appeared to be different in the 13 years older unilateral transplant than the bilateral ones $(\mathrm{p}=0.005)$.

As to previous disease, the single-lung transplant group presented higher amount of pulmonary fibrosis, while the double-lung transplant group presented more cystic fibrosis, bronchiectasis, lymphangioleiomyomatosis and pulmonary hypertension. The only condition with similar amount of unilateral and bilateral transplants in our casuistic is the pulmonary emphysema. 
Table 1. Demographic data of lung transplant recipients: Single vs Doublelung transplant. (alpha $=0.05$ )

\begin{tabular}{lccc}
\hline & $\begin{array}{c}\text { Single-lung } \\
\mathbf{N}=\mathbf{1 1}\end{array}$ & $\begin{array}{c}\text { Double-lung } \\
\mathbf{N}=\mathbf{1 8}\end{array}$ & \\
\hline Sex & $4 \mathrm{~F} 7 \mathrm{M}$ & $5 \mathrm{~F} 13 \mathrm{M}$ & $\mathrm{p}=0.694$ \\
Age (ys) & $53.9+/-7.10$ & $40.83+/-12.86$ & $\mathrm{p}=0.005$ \\
Height (cm) & $160+/-9.06$ & $164+/-8.0$ & $\mathrm{p}=0.206$ \\
Weight (Kg) & $61.09+/-10.75$ & $58.55+/-12.32$ & $\mathrm{p}=0.578$ \\
FVC \% & $54.27+/-7.70$ & $40.23+/-12.45$ & $\mathrm{p}=0.002$ \\
FEV1\% & $44.11+/-18.59$ & $23.68+/-9.18$ & $\mathrm{p}<0.001$ \\
\hline Disease & & & $\mathrm{p}=0.007$ \\
\hline Emphysema & 5 & 4 & \\
Pulmonary Fibrosis & 6 & 1 & \\
Bronchiectasis & & 6 & \\
Cystic Fibrosis & & 5 & \\
Lymphangioleiomyomatosis & & 1 & \\
Pulmonary Hipertension & & & \\
\hline
\end{tabular}

Post-transplant lung function evolution:

The increase in the lung function among the double-lung transplant group was more premature, with statistical difference from the 1st month both in the FEV1 (Figure 1) and FVC (Figure 2) compared to the pre-transplant amounts ( $p<0.05$ ). The CVF of this group increasingly persisted along one year, finding a significant increase between values in the 9th and 12th month, compared to the first post-operative month ( $\mathrm{p}<0.05)$.

In the single-lung transplant group, there was a significant increase in FVC after 3 months $(\mathrm{p}=0.002)$ and in FEV1 after 6 months $(p=0.004)$. After that period, FEV1 and FVC in the unilateral group did not vary significantly along the follow-up.

Comparison of the post-transplant FEV1 and FVC (1, 3, 6, 9, and 12 months) between unilateral and bilateral groups did not show statistically significant difference. Both groups improved as to the functional point of view.

The bilateral transplant group had a proportionally higher gain, since their pre-transplant lung function was more compromised. The gain in FEV1 in the double-lung transplant comparing to the lung function after 1 year versus the preoperative amount was 3.75 times against 1.66 times in the single-lung group ( $p<0.001)$. FVC increased 2.14 times in the bilateral group against 1.37 times of the unilateral one $(\mathrm{p}<0.001)$.

\section{Sub-group of emphysema patients:}

During the period analyzed in our study, 9 patients with pulmonary emphysema were subjected to pulmonary transplant, 5 single-lung and 4 double-lung transplants. Therefore, it was possible to compare both techniques in this sub-group of patients.

Upon the comparison of pre-transplant variables from each group, there was no observed difference as to the age, height, weight or pulmonary function (Table 2).

Figures 3 and 4 show the evolution of functional data (FVC and FEV1) along 1 year with the emphysema patients subjected to pulmonary transplant.
Figure 1. Forced vital capacity of lung transplant recipients (Single vs Double-lung)

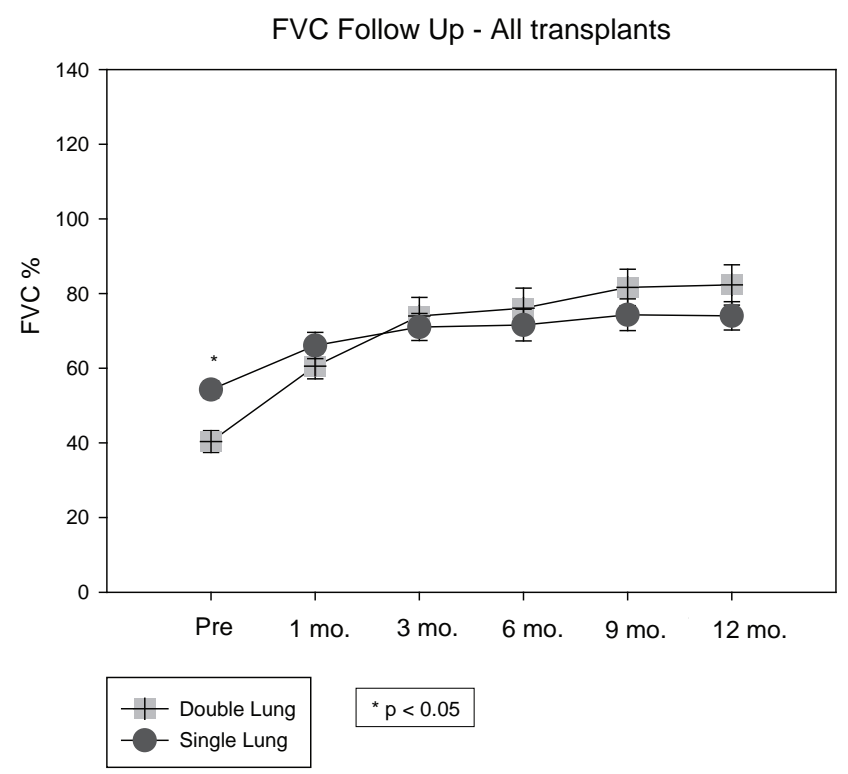

Figure 2. Expiratory forced volume in one second of lung transplant recipients (Single vs Double-lung)

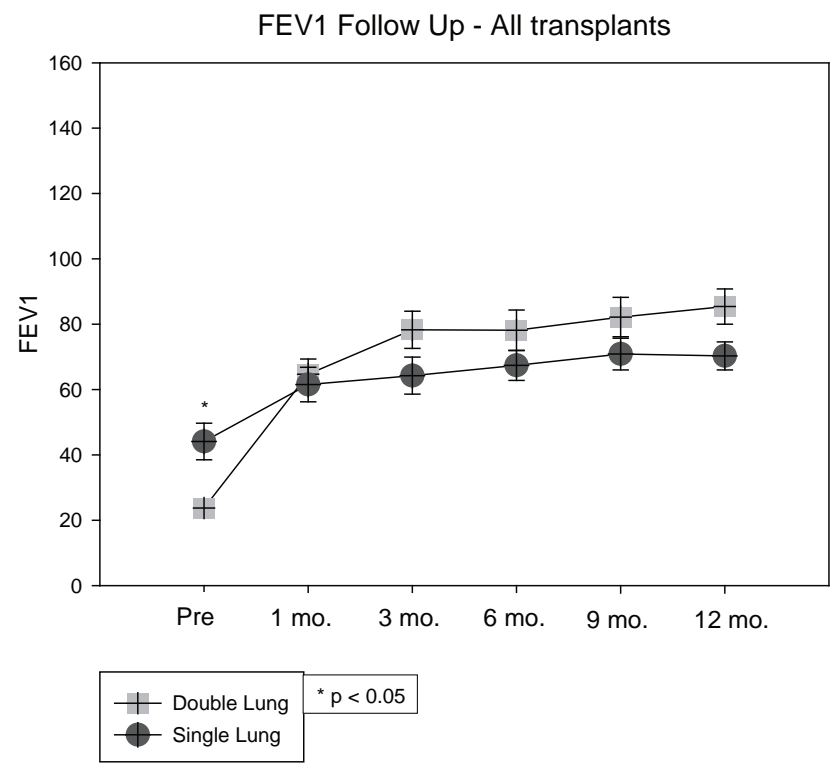

There was no significant variation in the FVC among the unilateral group in the post-transplantation months compared to the pretransplant amounts $(\mathrm{p}=0.861)$. For the same group, the FEV1 post-transplants presented an increase from month 6 , which was maintained in the subsequent assessment $(p=0.002)$.

The double-lung transplant group showed significant increase in FVC and FEV1 from the third post-transplant month $(\mathrm{p}<0.001$ and $\mathrm{p}=0.002$ ).

Comparison between both groups shows that from the 3rd month on, there is a difference in the lung function. The unilateral transplant 
Table 2. Demographic data of lung transplant emphysema recipients: Single vs Double-lung transplant (alpha=0.05).

\begin{tabular}{lccl}
\hline & $\begin{array}{c}\text { Single-lung } \\
\mathbf{N}=\mathbf{5}\end{array}$ & $\begin{array}{c}\text { Double-lung } \\
\mathbf{N}=\mathbf{4}\end{array}$ & \\
\hline Sex & $3 \mathrm{~F} 2 \mathrm{M}$ & $4 \mathrm{M}$ & $\mathrm{p}=1.000$ \\
Age (ys) & $52.2+/-8.13$ & $56.25+/-6.39$ & $\mathrm{p}=0.444$ \\
Height (cm) & $155+/-9.0$ & $165+/-7.1$ & $\mathrm{p}=0.128$ \\
Weight (Kg) & $55.4+/-7.4$ & $63.8+/-16.2$ & $\mathrm{p}=0.331$ \\
FVC \% & $52.98+/-8.70$ & $51.02+/-11.73$ & $\mathrm{p}=0.781$ \\
FEV1\% & $27.15+/-5.58$ & $21.08+/-4.75$ & $\mathrm{p}=0.128$ \\
\hline
\end{tabular}

Figura 3. Forced vital capacity of lung transplant emphysema recipients (Single vs Double-lung)

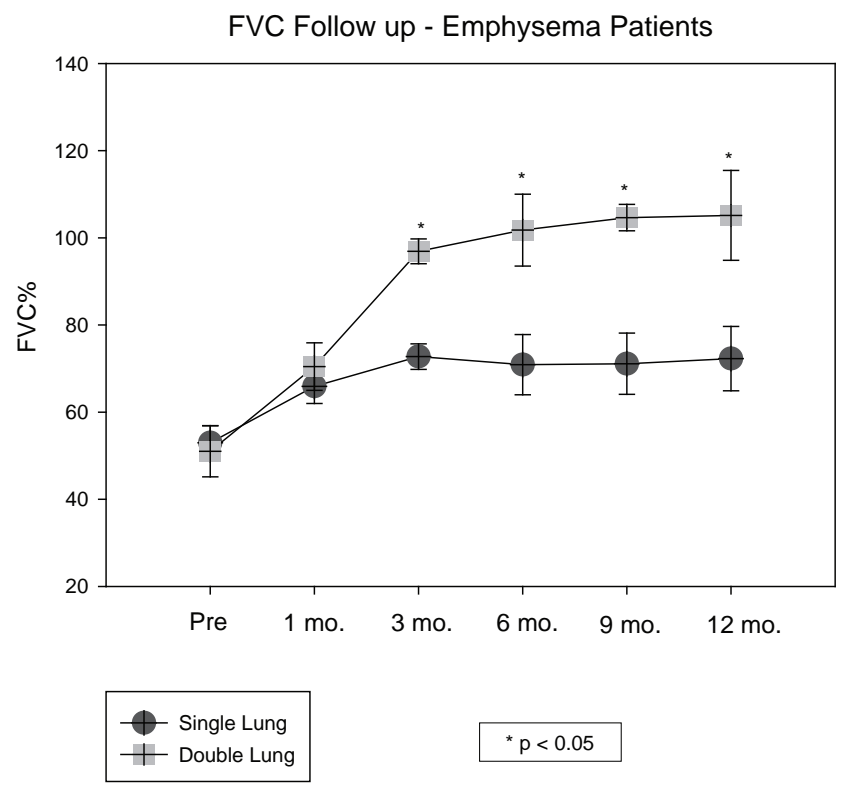

Figura 4. Forced expiratory volume in one second of lung transplant emphysema recipients (Single vs Double-lung)

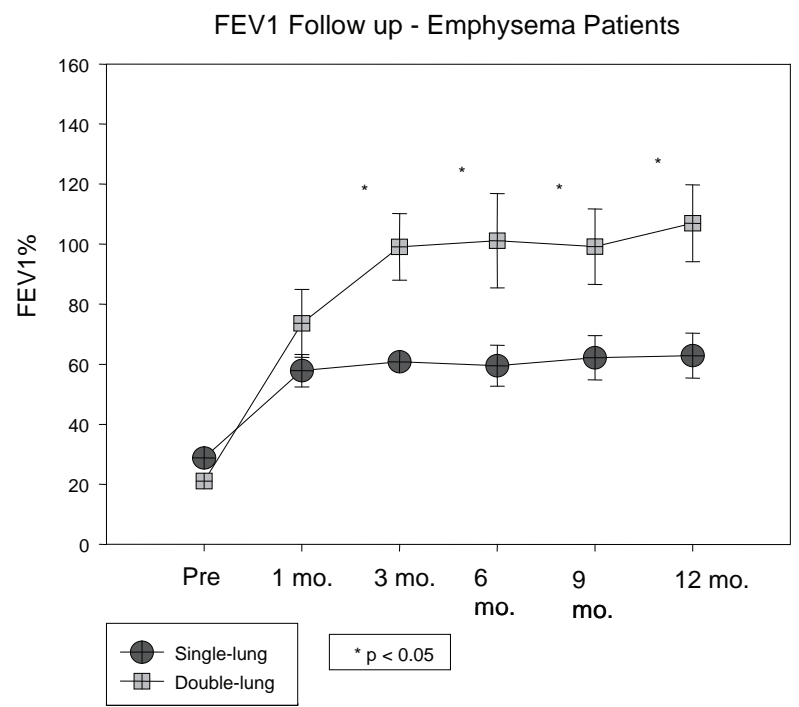

group with mean $72,7+/-5,8 \%$ CVF forecasted and bilateral with $96,8+/-5,6 \%(p=0.001)$. This finding is repeated when comparing the FEV1. Unilateral with 53.4/-15.1\% and bilateral with 99.1/-22.2 $\%(\mathrm{p}=0.015)$.

The difference in the lung function between groups is maintained in the 6, 9 and 12 months of measurement.

\section{DISCUSSION}

This study observed the spirometric evolution of the lung transplanted patients after one year, comparing the single-lung and double-lung transplant. Both analysis of the whole group and the sub-group of emphysema patients supplied relevant data that adds landmarks to the advantages of the bilateral over the unilateral transplant.

Values of FVC and FEV1 pre-transplant were lower in patients who undergone by double-lung transplant compared to the unilateral transplant. Concerning the selection of patients with cystic fibrosis and bronchiectasis, they were generally young and presented worst impairment of the lung function in the bilateral transplant.

Although the amounts of the pre-transplant lung function were worse in the double-lung group, this difference did not occur again in the subsequent months followed the surgery. After one year of follow-up, the mean gain of 2.14 times the initial amount of FVC, 3.75 times of FEV1 in bilateral transplant patients, 1.37 times the initial amount of FVC, and 1.66 times of FEV1 in unilateral transplant. ( $\mathrm{P}=0.004$ and $\mathrm{P}=0.001)$.

With a different initial lung function, it has been shown that after one month, both groups were equal up to the end of the first year. There was no statistical or clinically significant difference. To sum it up, the double-lung transplant patients, despite the worse initial lung function presented a performance at least equal to the singlelung ones along the follow-up.

When analyzing separately the group of the emphysema patients, it is possible to compare both modalities of transplant in patients with similar anthropometric characteristics and the preoperative function. In patients with similar characteristics, the double-lung transplant showed higher and more premature increase in the lung function showing advantages over the single-lung after the 3rd post-transplant month.

There is no consensus as to the right moment to perform the transplant in COPD. The current recommendation to include only those patients with severe COPD and respiratory insufficiency is the most appropriate, since the mortality rate is high in this population ${ }^{10,11}$.

Approximately $40 \%$ of the current pulmonary lung transplants are carried out for advanced pulmonary emphysema ${ }^{15}$. It is not yet clearly established the advantages of the bilateral proceeding in this group. There is evidence that in the single-lung transplants the hyperinsufflation of the native lung can lead to imbalance the ventilation / perfusion ratio with serious negative hemodynamic consequences. ${ }^{20}$

As to the mortality, the literature has shown that the single-lung transplantation was more often than that of patients who received double-lung transplantation $(\mathrm{p}<0,017)$. Furthermore, the risk of death among the emphysema patients receiving a single-lung transplant was nine-fold higher than patients who received double- 
Table 3. Lung Function values in all single and double-lung transplant during follow-up. Values expressed in \% predicted.

\begin{tabular}{|c|c|c|c|c|c|c|c|}
\hline Variable & Transplant & PRE & $1 \mathrm{mo}$. & $3 \mathrm{mo}$. & $6 \mathrm{mo}$. & $9 \mathrm{mo}$. & $12 \mathrm{mo}$. \\
\hline \multirow[t]{2}{*}{ FVC } & Single & $55,71 \% \square$ & $65,55 \%$ & $73,99 \%$ * & $76,66 \%$ * & $79,01 \%$ * & $77,37 \%$ * \\
\hline & Double & $40,37 \%$ & $59,06 \%$ * & $72,22 \%^{*}$ & $76,10 \%^{*}$ & $81,64 \%^{*}$ & $82,31 \% *$ \\
\hline \multirow[t]{2}{*}{ FEV1 } & Single & $44,11 \% \square$ & $61,55 \%$ & $64,26 \%$ * & $67,39 \%{ }^{*}$ & $70,86 \%{ }^{*}$ & $70,29 \%$ * \\
\hline & Double & $23,72 \%$ & $62,41 \%$ * & $76,53 \%{ }^{*}$ & $78,13 \%{ }^{*}$ & $82,17 \%$ * & $85,41 \%$ * \\
\hline
\end{tabular}

\footnotetext{
$\square$ Statistical significant difference between single and double transplan

* Statistical significant difference compared to pre-transplant values

Alpha $=0.05$
}

lung at the transplant. ${ }^{14}$ Still, we can mention that the improved long-term survival of double-lung transplantation over singlelung transplantation in emphysema patients remains a favorable prognostic factor in the International Society of Heart and Lung Transplantation (ISHLT) registry 15.

In our study, patients with emphysema showed that the preoperative amounts of FVC and FVE1 were similar to the literature. A series of 306 recipients reported by Cassivi et al showed a mean FVC and FEV 1 of $51 \%$ and $16 \%$ of the forecast, respectively. ${ }^{21}$ Still, in this study, the mean values raised to $84 \%$ and $79 \%$ forecasted to the 1 year follow-up. This difference is significant. Our study presented a significant increase of those same amounts. However, this fact occurred for FEV1 and FVC in double-lung transplantation from the third month and only for FEV1 from $6^{\circ}$ month in single-lung transplantation. Ferrer et $\mathrm{al}^{7}$ reported the mean amounts of FVC and FVE1 were $41.8 \%$ and $21.1 \%$ to predicted, at a sample with 65 patients with Emphysema.

A factor that must be considered is that if patients who underwent by single-lung transplant did not present a better performance in the postoperative examinations due to the progression of the disease in the native lung because of the hyperinflation in the remaining lung.

Hyperinflation of the native lung is defined as a swing in the mediastinum towards the grafted lung, with rectification of the ipsilateral diaphragm, leading to a mechanical disadvantage in the ventilation, which can also cause a hemodynamic worsening due to the increased thoracic pressures. This is a factor associated to the lowest amount of FVC and FEV1 of unilateral transplants, especially in obstructive diseases. ${ }^{22}$

The spirometric results were better for recipients in the group of bilateral-lung transplantation. The hyperinflation above discussed, could be a reason to the reduction in the amounts of the single-lung transplantation. We do not know whether patients with Pulmonary Fibrosis and other diseases treated with double-lung transplantation would have the same behavior than patients with emphysema, since in our sample six patients received double-lung transplantation and only one received single-lung transplantation.

Other reason that could be responsible by the significant difference is only the presence of the native lung regardless the LHI, as it was mentioned above, which slows the progression of the disease. Moreover, in cases of double-lung transplantation, both lungs are replaced, then reducing the influence of the pulmonary disease.

\section{CONCLUSION}

There was a significant improvement in the lung function both in unilateral and bilateral transplant after one year. There was a clear tendency towards a higher and more premature improvement in FVC and FEV1 in the bilateral transplant group. More patients as well as a longer follow-up are necessary in order to confirm the facts which were presented.

\section{RESUMO}

Objetivo: A proposta deste estudo foi comparar dados espirométricos entre pacientes submetidos a transplante pulmonar unilateral e bilateral. Introdução: O transplante pulmonar, inicialmente descrito como método experimental em 1963, transformou-se em opção terapêutica para alguns pacientes com pneumopatia terminal. Isso ocorreu devido ao aperfeiçoamento das técnicas de preservação e operatórias, terapia imunossupressora e manejo de infecções pós-operatórias. Métodos: Foram revisados retrospectivamente 39 prontuários de pacientes submetidos a transplante pulmonar em nossa instituição entre agosto de 2003 e agosto de 2006. Destes, 29 pacientes apresentaram sobrevida de um ano, no mínimo. Esses 29 pacientes foram avaliados. Resultados: A função pulmonar aumentou mais precocemente em pacientes submetidos a transplante bilateral, com significância estatística a partir do $1^{\circ}$ mês para VEF1 e CVF, em comparação com os valores pré-transplante $(\mathrm{p}<0,05)$. Nos pacientes portadores de enfisema, a comparação entre os pacientes submetidos a transplante unilateral e bilateral mostrou diferença a partir do $3^{\circ}$ mês. Discussão: As análises dos grupos e do subgrupo com enfisema sugerem superioridade do transplante bilateral em relação ao unilateral. Apoiando essa tendência, os valores da função pulmonar pré-transplante eram piores no grupo bilateral, porém essa diferença não persistiu nos meses subseqüentes ao procedimento. Conclusão: Há clara tendência de ganho maior e mais precoce de função pulmonar no grupo de pacientes que foram submetidos ao transplante bilateral.

Descritores: Transplante de Pulmão; Espirometria; Testes de Função Respiratória; Enfisema 


\section{REFERENCES}

1. Maurer JR, Frost AE, Estenne M, Higenbottam T, Glanville AR. International guidelines for the selection of lung transplant candidates. The International Society for Heart and Lung Transplantation, the American Thoracic Society, the American Society of Transplant Physicians, the European Respiratory Society. Transplantation. 1998 Oct 15;66(7):951-6.

2. The Toronto Lung Transplant Group. Experience with single-lung transplantation for pulmonary fibrosis. JAMA. 1988 Apr 15;259(15):2258-62.

3. Pochettino A, Kotloff RM, Rosengard BR, Arcasoy SM, Blumenthal NP, Kaiser LR, et al. Bilateral versus single-lung transplantation for chronic obstructive pulmonary disease: intermediate-term results. Ann Thorac Surg. 2000 Dec;70(6):1813-8; discussion 8-9.

4. Murray CJ, Lopez AD. Alternative projections of mortality and disability by cause 19902020: Global Burden of Disease Study. Lancet. 1997 May 24;349(9064):1498-504.

5. Nocturnal Oxygen Therapy Trial Group. Continuous or nocturnal oxygen therapy in hypoxemic chronic obstructive lung disease: a clinical trial. Ann Intern Med. 1980 Sep;93(3):391-8.

6. Long term domiciliary oxygen therapy in chronic hypoxic cor pulmonale complicating chronic bronchitis and emphysema. Report of the Medical Research Council Working Party. Lancet. 1981 Mar 28;1(8222):681-6.

7. Ferrer J, Rodriguez E, Roman A, Bravo C, Roldan J, Hermosilla E, et al. Factors related to postoperative mortality in lung transplantation for emphysema. Transplant Proc. 2007 Dec;39(10):3317-22.

8. Chu CM, Chan VL, Lin AW, Wong IW, Leung WS, Lai CK. Readmission rates and life threatening events in COPD survivors treated with non-invasive ventilation for acute hypercapnic respiratory failure. Thorax. 2004 Dec;59(12):1020-5.

9. Geertsma A, Ten Vergert EM, Bonsel GJ, de Boer WJ, van der Bij W. Does lung transplantation prolong life? A comparison of survival with and without transplantation. J Heart Lung Transplant. 1998 May;17(5):511-6.

10. Thabut G, Mal H, Castier Y, Groussard O, Brugiere O, Marrash-Chahla R, et al Survival benefit of lung transplantation for patients with idiopathic pulmonary fibrosis. J Thorac Cardiovasc Surg. 2003 Aug;126(2):469-75.

11. Charman SC, Sharples LD, McNeil KD, Wallwork J. Assessment of survival benefit after lung transplantation by patient diagnosis. J Heart Lung Transplant. 2002 Feb;21(2):226-32.
12. Hosenpud JD, Bennett LE, Keck BM, Edwards EB, Novick RJ. Effect of diagnosis on survival benefit of lung transplantation for end-stage lung disease. Lancet. 1998 Jan 3;351(9095):24-7.

13. Mal H, Andreassian B, Pamela F, Duchatelle JP, Rondeau E, Dubois F, et al. Unilateral lung transplantation in end-stage pulmonary emphysema. Am Rev Respir Dis. 1989 Sep;140(3):797-802.

14. Angles R, Tenorio L, Roman A, Soler J, Rochera M, de Latorre FJ. Lung transplantation for emphysema. Lung hyperinflation: incidence and outcome. Transpl Int. 2005 May;17(12):810-4.

15. Trulock EP, Christie JD, Edwards LB, Boucek MM, Aurora P, Taylor DO, et al. Registry of the International Society for Heart and Lung Transplantation: twentyfourth official adult lung and heart-lung transplantation report-2007. J Heart Lung Transplant. 2007 Aug;26(8):782-95.

16. Martinez JA, Paradis IL, Dauber JH, Grgurich W, Richards T, Yousem SA, et al. Spirometry values in stable lung transplant recipients. Am J Respir Crit Care Med. 1997 Jan;155(1):285-90.

17. Mason DP, Rajeswaran J, Murthy SC, McNeill AM, Budev MM, Mehta AC, et al. Spirometry after transplantation: how much better are two lungs than one? Ann Thorac Surg. 2008 Apr;85(4):1193-201, 201 e1-2.

18. Knudson RJ, Lebowitz MD, Holberg CJ, Burrows B. Changes in the normal maximal expiratory flow-volume curve with growth and aging. Am Rev Respir Dis. 1983 Jun;127(6):725-34.

19. Miller MR, Crapo R, Hankinson J, Brusasco V, Burgos F, Casaburi R, et al. General considerations for lung function testing. Eur Respir J. 2005 Jul;26(1):153-61.

20. Stevens PM, Johnson PC, Bell RL, Beall AC, Jr., Jenkins DE. Regional ventilation nd perfusion after lung transplantation in patients with emphysema. N Engl J Med. 1970 Jan 29;282(5):245-9.

21. Cassivi SD, Meyers BF, Battafarano RJ, Guthrie TJ, Trulock EP, Lynch JP, et al. Thirteen-year experience in lung transplantation for emphysema. Ann Thorac Surg. 2002 Nov;74(5):1663-9; discussion 9-70.

22. Yonan NA, el-Gamel A, Egan J, Kakadellis J, Rahman A, Deiraniya AK. Single-lung transplantation for emphysema: predictors for native lung hyperinflation. J Heart Lung Transplant. 1998 Feb;17(2):192-201. 